\title{
SIMULATION-BASED PREDICTING THE POSITION OF ROAD TANK EXPLOSIONS. PART I: DATA AND MODELS
}

\author{
Egidijus Rytas Vaidogas ${ }^{1}$, Lina Linkutè ${ }^{2}$, Dainius Stulgys ${ }^{3}$ \\ ${ }^{1,2}$ Dept of Occupational Safety and Fire Protection, Vilnius Gediminas Technical University, \\ Sauletekio al. 11, LT-10223 Vilnius, Lithuania \\ ${ }^{3}$ Lithuanian Technology Platform on Industrial Safety, P.O. Box 2846, VACP, \\ Gedimino pr. 7, LT-01008 Vilnius, Lithuania \\ E-mails: 1erv@vgtu.lt (corresponding author); 2 lina.linkute@vgtu.lt; ${ }^{3}$ dainius.stulgys@danis.lt
}

Submitted 14 June 2011; accepted 27 September 2011

\begin{abstract}
Road tankers used for the transportation of flammable liquids and liquefied gases can be involved in accidents which escalate into fires and the so-called boiling liquid expanding vapour explosions. The damaging effects of these phenomena on roadside property depend on the position and orientation of exploding tanks in relation to vulnerable roadside objects. This study presents a simulation-based approach to the prediction of the position of road tank explosions. The position is expressed by longitudinal and transverse rest position of an exploding tank as well as departure angle of the tank. As a part of this study, data on transverse rest position and departure angle was collected and used to fit probability distributions which express uncertainties in these circumstantial characteristics of road tank accidents. It was found that data on the longitudinal rest position is difficult to obtain and modelling this accident characteristic will have to rely on a subjective specification of probability distributions. Such distributions can be chosen by applying approaches used in the field of quantitative risk assessment. Probability distributions, partly subjective and partly based on hard data, are applied to simulate values of potential explosion coordinates. The simulation results have the premise to be applied to forecasting mechanical and thermal effects of explosions on road and assessing damage from them. A case study used to evaluate the performance of the models proposed in this study is presented in the second part of the paper.
\end{abstract} proach.

Keywords: explosion, BLEVE, fire, simulation, road accident, road tank, risk, hazardous material, Bayesian ap-

\section{Introduction}

Every day large amounts of hazardous materials are transported by road tanks. Accidents of these vehicles pose serious risk to road traffic and roadside territory (Planas-Cuchi et al. 2004; Oggero et al. 2006). In an extreme case a road tank accident can end up in a severe explosion known as BLEVE (boiling liquid expanding vapour explosion) (Abassi, T., Abassi, S. 2007; Taveau 2010). A BLEVE on road can be a stand-alone accident or, alternatively, cause secondary or 'knock-on' accidents in the roadside territory (Abdolhamidzadeh et al. 2010, 2011).

A prediction of BLEVE effects on roadside property is possible by means of mathematical modeling. The models of BLEVE effects cover blast, fireballs, and projection of fragments (projectiles) (e.g., CCPS 1994; Casal 2007). Most of these models are strictly deterministic; some models include probabilistic elements
(Hauptmanns 2001; Vaidogas 2006; Mébarki et al. 2009; Nguyen et al. 2009). The key input information of them is of geometric nature. The prediction of BLEVE effects requires knowing the distance and orientation of the tank in relation to potential targets of BLEVE (e.g., Birk 1996; Casal 2007). The identification of the position and orientation is particularly important when the potential distance between tank and target is relatively small.

As BLEVEs of road tanks are relatively rare and unexpected events influenced by many random factors, the prediction of the tank position and orientation at the instant of BLEVE will have to deal with considerable uncertainties. Methods of quantitative risk assessment (QRA) are naturally suited to quantify and propagate such uncertainties. Quantitative measures of uncertainties in position and orientation of exploding tank can serve as input into a QRA problem which will relate BLEVE to its risk profile. 
There is a history of applications of QRA to transportation of hazardous materials or transportation risk assessment (TRA) (CCPS 1995; CPD 1999; Fabiano et al. 2002; Bubbico et al. 2004a, 2004b; Gheorghe et al. 2005). The common features of these applications are as follows:

1. Large traffic fragments are considered and divided into smaller route segments, for which risk is estimated. The method of route disaggregation varies in different applications.

2. Methods used for the estimation of risk related to individual route segments are in most cases suitable for fixed installations.

3. Most applications deal with individual and societal risk to exposed population. Risk to built roadside property (buildings, objects of traffic infrastructure, industrial installations) is mentioned but not considered in detail.

4. The accident scenario prevailing in the applications of TRA is a release of toxic materials and subsequent intoxication of population. Fires and explosions are not considered in detail, especially in the context of risk to fixed roadside objects.

5. When it comes to a fire and/or explosion accident on road and rail, authors often simply refer to models proposed in the literature for the prediction of effects of these phenomena, for instance, to the 'coloured' books issued by the Dutch organisation TNO (CPD 1992, 2005). Attempts to relate in detail characteristics of traffic accidents to fires and explosions on road and rail are not known to us.

6. Methodological aspects of QRA applications to TRA look 'suspiciously flat'. Applications of TRA have few if any considerations on the uncertainty of risk assessments, quality and relevance of data, formal separation of experts' opinions and hard historical data.

In summary, one can say that TRA is a widely developed extension of QRA; however, applications of TRA lack 'attention to detail', where fires and explosions on road and rail are of concern. A BLEVE-related example of this state of investigations is the assessment of individual and societal risk due to LPG transportation done by Paltrinieri et al. (2009).

The idea that explosions and fires on road and rail may require an in-depth consideration of the risk to a specific object built in the vicinity of the route with the hazard of fire and explosion accidents is not new. Gheorghe et al. (2005) and Vaidogas (2007a) considered specific situation of exposure of roadside objects to fires and explosions on road and rail. The present study can be viewed as a refining of these approaches.

We think that the assessment of risk to specific roadside property posed by road tank explosions requires a detailed simulation of the road accident preceding the BLEVE event. Results of such simulation will yield input information for the simulation-based prediction of BLEVE effects and eventually potential damage to roadside objects. The simulation results can be useful for a risk-based design of barriers which could provide protection against BLEVEs. The present study focuses on a stochastic (Monte Carlo) simulation of position and orientation of road tanks before they undergo an explosion.

This study is comprised of two parts. The first part contains a description of a data on the rest position of road tanks involved in traffic accidents. Probabilistic models fitted to this data are presented as well. Finally, the first part presents considerations on the stochastic simulation of the accident position. The second part describes a case study used to illustrate the simulation procedure (see next issue of the Journal).

\section{Risk Related to Road Tank Explosions}

In terms of QRA, a BLEVE accident of a road tank is a low-probability initiating event. It can be internal or external event with respect to exposed installation (e.g., Kumamoto 2011; Garrick 2008). QRA can be focused on a specific random damage event $D$, for instance, loss of containment of a tank or rupture of a pipeline due to mechanical and thermal actions of BLEVE. In this case the frequency of $D$ can be expressed as a product of transportation frequency (mission frequency) $F(M)$ and three conditional probabilities which relate $M$ to $D$ :

$$
F(D)=F(M) P(A \mid M) P(B \mid A) P(D \mid B),
$$

where: $A$ is the random event of a road accident, in which the road tank will be involved, and $B$ is the random event of BLEVE.

The estimation of the conditional damage probability $P(D \mid B)$ requires to assess mechanical and thermal effects of BLEVE. If these effects are grouped into a vector $y$, the damage probability can be expressed as follows (Vaidogas, Juocevičius 2009):

$P(D \mid B)=\int_{\text {all } y} P(D \mid \boldsymbol{y}) f(\boldsymbol{y}) d \boldsymbol{y}=\int_{\text {all } \boldsymbol{x}} P(D \mid \boldsymbol{\psi}(\boldsymbol{x})) f(\boldsymbol{x}) d \boldsymbol{x}$,

where: $P(D \mid y)$ is the fragility function relating the probability of $D$ to $y ; x$ is the vector of characteristics of BLEVE accident; $\psi(x)$ is the vector-function which relates $\boldsymbol{x}$ to $\boldsymbol{y}$ (i.e., $\boldsymbol{y}=\boldsymbol{\psi}(\boldsymbol{x})$ ); and $f(\boldsymbol{x})$ and $f(\boldsymbol{y})$ are the joint probability density functions of $\boldsymbol{x}$ and $\boldsymbol{y}$, respectively.

The development of the fragility function $P(D \mid y)$ is a highly case-specific task of reliability-based structural analysis. It must be solved for individual components of installation subjected to the hazard of BLEVE (e.g., Vaidogas 2003, 2007a, 2007b). The development of $P(D \mid \boldsymbol{y})$ will not be considered here. We can only say that a BLEVE accident may require to develop $P(D \mid y)$ for a combined action of three effects (components of $\boldsymbol{y}$ ): blast wave, thermal radiation and missile impact. Any attempts to do this are not known to us. The closest result was obtained by Lee, Rosowski (2006) who developed a fragility function for a combined action of earthquake and snow. 
Fitting the density $f(y)$ to the direct data on BLEVE effects is impracticable. BLEVE accidents on road are unique, short-lasting and unexpected events and the post mortem data on them is too sparse for fitting $f(\boldsymbol{y})$. However, the density $f(y)$ and so the probability $P(D \mid B)$ can be estimated by propagating uncertainties expressed by the lower-level density $f(\boldsymbol{x})$ through the model $\boldsymbol{\psi}(\boldsymbol{x})$ (Vaidogas 2007a, 2007b, 2009; Vaidogas, Juocevičius 2008a, 2008b, 2009; Juocevičius, Vaidogas 2010). The function $\psi(x)$ can be composed of a relatively large number of models available currently for the prediction of individual effects of BLEVE. Most of these models are deterministic; some are in competition in modelling individual effects. Table 1 contains a selection of literature on modelling the effects of BLEVE.

The density $f(x)$ expresses uncertainties in those characteristics of BLEVE accident which serve as input in the model $\boldsymbol{\psi}(\boldsymbol{x})$. This density can be specified by means of two basic approaches to QRA known as classical Bayesian approach and predictive Bayesian approach (e.g., Aven 2003). We think that the latter approach is better suited to the assessment of risk posed by BLEVEs on road. However, an extensive discussion on the choice among the classical and predictive approaches will not be presented here. Such a discussion can be found in publications dedicated to methodological issues of QRA (e.g., Aven 2009; Aven, Zio 2011). All probabilistic models presented in the subsequent text will be interpreted in line with the predictive Bayesian approach.

The vector $\boldsymbol{x}$ must contain physical characteristics of the tank undergoing BLEVE. The effects of BLEVE will also depend on the position and orientation of the tank in relation to the target. A scattering of projectiles from a cylindrical vessel BLEVE is significantly directional; some studies indicate that the blast from BLEVEs can also be directional (Birk 1996; Casal 2007). The position and orientation are key input information for the models described in the references cited in Table 1. In what follows, the position and orientation of the tank will be expressed by the first three components of $x$ :

1. The coordinates of explosion (tank) centre, $x_{1}$ and $x_{2}$, specified in a coordinate system which includes the target and the section of the road in which the explosion can happen (Fig. 1).

2. The angle of the tank axis in relation to the road axis, $x_{3}$ (Fig. 1).

The further consideration is about the prediction of $x_{1}, x_{2}$, and $x_{3}$ for a specific situation of exposure to BLEVE hazard, and thus the prediction of the distance from the explosion to a target under analysis. This distance will be denoted by $\Delta$ (Fig. 1). Despite the fact that the dimensions $x_{1}, x_{2}$ and $x_{3}$ are not among physical characteristics of exploding tank, the proper choice of range and probability distribution of $x_{1}, x_{2}$ and $x_{3}$ can substantially influence results of further risk assessment.

\section{Geometric Information on Road Tank Accidents}

The position and orientation of the tank after a road accident which escalates into BLEVE is growing in importance when the distance between tank and target decreases. Two coordinate systems can be used for the prediction of tank position and orientation (Franck H., Franck, D. 2010). The assessment of the risk to a fixed target requires to consider the position and orientation in the earth-fixed coordinate system $\left\{0 ; x_{1}, x_{2}, x_{3}\right\}$ (Fig. 1). However, the data on road tank accidents can be collected and processed using a coordinate system based on both vehicle and travel lane, $\left\{0 ; y_{1}, y_{2}, y_{3}\right\}$ (Fig. 2). The data recorded in the latter system can be transformed into data related to the former one with relative ease.

\subsection{Transverse Rest Position and Departure Angle}

The prediction of the tank position and orientation after it comes to a complete stop and can explode consists in the choice of either joint probability density function $f\left(y_{1}, y_{2}\right)$ or marginal densities $f\left(y_{1}\right)$ and $f\left(y_{2}\right)$ for the transverse rest position of the tank centre, $y_{1}$, and the angle of rest departure of the tank relative to the travel lane centreline, $y_{2}$ (Fig. 2). For brevity, we will call $y_{1}$ and $y_{2}$ the transverse rest position and departure angle, respectively. In line with the aforementioned approaches to QRA, the densities $f\left(y_{1}, y_{2}\right)$ or $f\left(y_{1}\right)$ and $f\left(y_{2}\right)$ can be chosen using data on past accidents or expert opinion or both. The data can provide answer to the question of a stochastic dependence of $y_{1}$ and $y_{2}$.

We think that the statistical variability of transverse rest position $y_{1}$ and departure angle $y_{2}$ can be assessed from data on road tank accidents. The potential data on $y_{1}$ and $y_{2}$ are of three sorts:

1. Data on road tank accidents which escalated into BLEVEs (A-data, for brevity).

2. Data on accidents which did not escalate into BLEVEs but were capable to do so in consequence of spill of flammable liquid or fire impinging the tank ('near misses' in terms of QRA) (B-data).

Table 1. A selection of literature on models used to predict BLEVE effects (components of the vector-function $\boldsymbol{\psi}(\boldsymbol{x})$ )

\begin{tabular}{ll}
\hline \multicolumn{1}{c}{ BLEVE effect } & \multicolumn{1}{c}{ References } \\
\hline Blast & $\begin{array}{l}\text { Prugh (1991); CCPS (1994); Planas-Chuci et al. (2004); CPD (2005); Abbasi, T., Abbasi, S. (2007); Casal, } \\
\text { Salla (2006); Casal (2007); Genova et al. (2008) }\end{array}$ \\
\hline Fireball & CCPS (1994); Prugh (1994); Robets et al. (2000); CPD (2005); Abbasi, T., Abbasi, S. (2007); Casal (2007) \\
\hline Projectiles & $\begin{array}{l}\text { Hauptmanns (2001); Gubinelli } \text { et al. (2004); CPD (2005); Vaidogas (2006); Abbasi, T., Abbasi, S. (2007); } \\
\text { Casal (2007); Genova et al. (2008); Gubinelli, Cozzani (2009); Mébarki } \text { et al. (2009); Nguyen } \text { et al. (2009) }\end{array}$ \\
\hline
\end{tabular}




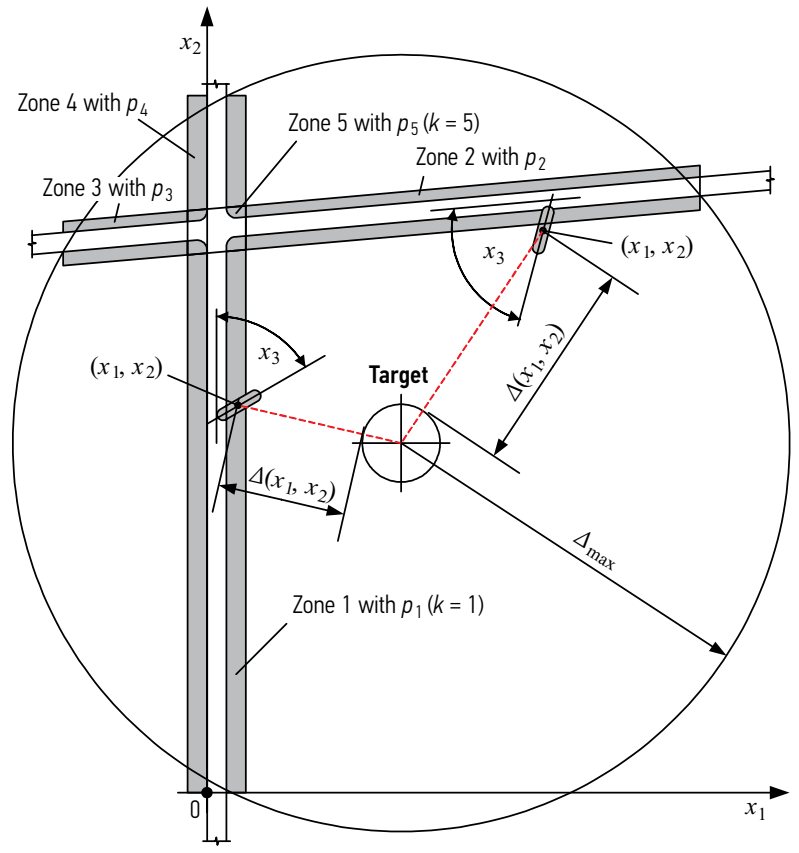

Fig. 1. Exposure of a roadside object (target) to the BLEVE hazard in the earth-fixed coordinate system $\left\{0 ; x_{1}, x_{2}, x_{3}\right\}$

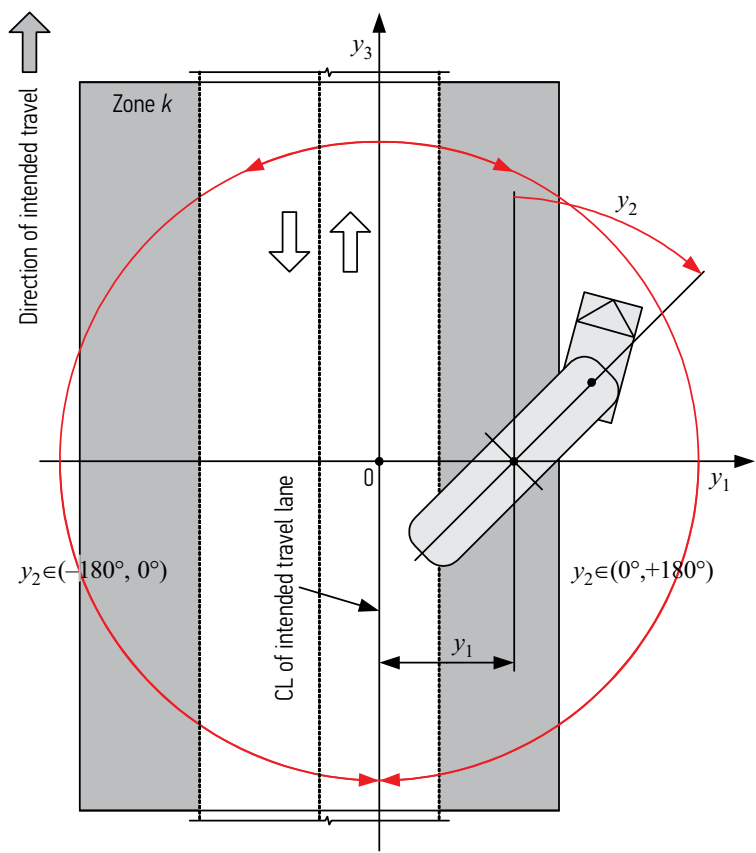

Fig. 2. Vehicle-based coordinate system $\left\{0 ; y_{1}, y_{2}, y_{3}\right\}$ used for collecting and processing data on road tank accidents

3. Data on accidents of road tanks which transported liquids, but not necessarily liquefied gases, and had dynamic characteristics similar to road tanks capable to cause BLEVE (C-data).

The A- and B-data are likely to be more relevant to future BLEVE accidents on road than C-data. However, the amount of $\mathrm{C}$-data exceeds considerably the amount of A- and B-data because the number of road accidents which developed into BLEVEs or occurred as "near misses" is relatively small (see, e.g., Oggero et al. 2006). In addition, information on $y_{1}$ and $y_{2}$ available in the reports on BLEVE accidents can be vague because tanks are displaced and destroyed during these explosions (see, e.g., Planas-Cuchi et al. 2004).

The potential sources of A-, B- and C-data are:

1. Hazmat transportation accident databases.

2. Accident databases of general nature.

3. Road accident databases collected and maintained usually by the police.

4. Databases of occupational accidents including road transportation events in which workers were injured and killed on duty.

These databases are maintained and updated by various official and professional bodies and organisations in many countries. However, several researchers have noticed the lack of statistical reliability of such databases due to the systematic underreporting of the circumstances of road accidents (see Trépanier et al. 2009 and the references cited therein). We think that a special study is necessary to determine whether these data sources contain such circumstantial data as a rest position $y_{1}$ and departure angle $y_{2}$ of the tank. To our knowledge, none of Lithuanian organisations maintains a database which includes circumstantial information on $y_{1}$ and $y_{2}$. We also did not find any freely accessible database maintained outside Lithuania which would contain data on $y_{1}$ and $y_{2}$.

Information on $y_{1}$ and $y_{2}$ can be elicited from the reports on road tank accidents presented by the massmedia and in the internet. These reports should not be neglected because they often contain pictures of the accident site and description accident circumstances. Consequently, such reports can serve as a source of C-data. We found a series of the reports and collected a small road tank accident database containing 151 events mainly for 2007-2011 period. Our database includes records of 65 accidents of the tank trucks and 86 accidents of tank semi-trucks. In 120 cases the accidents took place in the area with flat or almost flat roadside territory and zero vertical grade (gradient). In 17 and 5 cases accidents occurred on downhill and uphill road segments, respectively. The vertical grade was difficult to assess in 9 cases. Most accidents occurred in the US and were reported by US media. An extraction from the database is presented in Table 2 .

The values of the transverse rest position, $y_{1 i}$, were determined visually for 129 events and the departure angle $y_{2 i}$ was obtained also visually for 122 events. The data allowed to form 119 observation pairs $\left(y_{1 i}, y_{2 i}\right)$ for the assessment of the stochastic dependence of $y_{1}$ and $y_{2}$. Table 3 contains descriptive measures of the samples $\left\{y_{1 i}, i=1,2, \ldots, 129\right\}$ and $\left\{y_{2 i}, i=1,2, \ldots, 122\right\}$. Fig. 3 shows the histograms of these two samples. The scatter diagram of the pairs $\left(y_{1 i}, y_{2 i}\right)$ is given in Fig. 4 . The correlation coefficient computed for the pairs $\left(y_{1 i}, y_{2 i}\right)$ was equal to 0.29 . The $p$-value in Fig. 4 indicates a statistically significant relationship between $y_{1}$ and $y_{2}$.

It was possible to fit two well-known probability distributions, normal and logistic, to the values $y_{1 i}$. 
Table 2. An extraction from a database containing information on 151 road tank accident

\begin{tabular}{|c|c|c|c|c|c|}
\hline Date & Location & Material & Quantity, $\mathrm{m}^{3}$ & $y_{1, \mathrm{~m}}$ & $y_{2}$, degs \\
\hline $06 / 12 / 2007$ & Everett & Gasoline & 35.58 & 0.0 & 0 \\
\hline $25 / 07 / 2009$ & Oak Park, Michigan & Diesel & 49.21 & 2.0 & 0 \\
\hline $22 / 10 / 2009$ & Indiapolis & Propane & 20 & 8.5 & 85 \\
\hline $23 / 10 / 2009$ & Fayetteville & Fuel & not reported & 2.0 & 0 \\
\hline $30 / 11 / 2009$ & Kansas City & Hydrochlorid acid & 20.41 & 2.0 & 340 \\
\hline $23 / 01 / 2010$ & Melville, New York & Fuel & 45.42 & 6.5 & 340 \\
\hline $25 / 01 / 2010$ & Monperlier, France & Fuel & not reported & -6.5 & 270 \\
\hline $01 / 04 / 2010$ & Chikago, Illinois & Fuel & not reported & 2.0 & 0 \\
\hline $02 / 04 / 2010$ & Burverde, Texas & Fuel & not reported & -3.0 & 260 \\
\hline $07 / 04 / 2010$ & Wamsutter, Wyoming & Crude oil & not reported & 0.0 & 0 \\
\hline $14 / 04 / 2010$ & Roy, Utah & Diesel & 28.39 & 9.0 & 270 \\
\hline $16 / 05 / 2010$ & Miami Gardens, Florida & Fuel oil & not reported & 2.0 & 0 \\
\hline $28 / 05 / 2010$ & Carona, Los Angeles & Gasoline & 33.31 & 3 & 0 \\
\hline $29 / 05 / 2010$ & Tynsborough, Massach. & Aerosol paint & not reported & 3 & 0 \\
\hline $22 / 06 / 2010$ & Foxboro, Mass. & Jet fuel & 41.64 & 5.0 & 45 \\
\hline $20 / 08 / 2010$ & Coloma, Michigan & Fuel & not reported & 8 & 340 \\
\hline $20 / 08 / 2010$ & Armold, Maryland & Fuel & not reported & 0 & -5 \\
\hline $21 / 08 / 2010$ & Arizona & Diesel & 18.9 & 15.0 & 50 \\
\hline $28 / 08 / 2010$ & Utah & Diesel & 28.39 & 8.5 & 90 \\
\hline $29 / 08 / 2010$ & Hamshire, Texas & Isobutane & 32.76 & 10.0 & 90 \\
\hline $03 / 09 / 2010$ & Dearborn County, Indiana & Phthalic anhydride molten & 15.14 & 13.0 & 40 \\
\hline $23 / 10 / 2010$ & Fayetteville & Fuel & not reported & 2 & 0 \\
\hline $29 / 10 / 2010$ & Albuquerque, New Mexico & Fuel & not reported & -5.0 & 280 \\
\hline $09 / 11 / 2010$ & California & Tar & not reported & 5.0 & 15 \\
\hline $20 / 12 / 2010$ & Utah & Crude oil & 40.33 & -5.0 & 310 \\
\hline
\end{tabular}

Table 3. Descriptive measures of the samples consisting of observations of transverse rest position $y_{1 i}$ and departure angle $y_{2 i}$

\begin{tabular}{lcc}
\hline \multicolumn{1}{c}{ Measure } & Positions $y_{1 i}$ & Angles $y_{2 i}$ \\
\hline Sample size & 129 & 122 \\
\hline Mean & $2.02 \mathrm{~m}$ & $2.83^{\circ}$ \\
\hline Std. deviation & $5.62 \mathrm{~m}$ & $56.8^{\circ}$ \\
\hline Minimum & $-12.25 \mathrm{~m}$ & $-170^{\circ}$ \\
\hline Maximum & $18 \mathrm{~m}$ & $180^{\circ}$ \\
\hline Skewness & 0.0551 & 0.119 \\
\hline Kurtosis & -0.1059 & 1.679 \\
\hline Stnd. skewness & 0.256 & 0.536 \\
\hline Stnd. kurtosis & -0.246 & 3.79 \\
\hline
\end{tabular}

Table 4. Goodness-of-fit tests for the sample of $y_{1 i}$ values

\begin{tabular}{lcc}
\hline \multicolumn{1}{c}{ Measure } & Normal & Logistic \\
\hline Kolmogorov-Smirnov $D_{n}$ & 0.05755 & 0.05320 \\
\hline Kolmogorov-Smirnov $p$ & 0.7863 & 0.8586 \\
\hline Shapiro-Wilk $W$ & 0.9851 & - \\
\hline Shapiro-Wilk $p$ & 0.7542 & - \\
\hline
\end{tabular}

Although neither of the distributions was rejected by standard goodness-of-fit tests, the logistic distribution Logistic $(2.02 \mathrm{~m}, 3.10 \mathrm{~m})$ fits the data better than the normal distribution $N\left(2.02 \mathrm{~m}, 31.6 \mathrm{~m}^{2}\right)$ (see Table 4 and Fig. 3a). Thus the logistic distribution will be used for the purposes of the simulation described in Sec. 4 .

The values $y_{2 i}$ do not seem to obey any standard probability distribution. An empirical distribution function of the sample of $y_{2 i}$ can be used as a tentative model for the purposes of simulation (e.g., Evans et al. 2000). This function is represented by the histogram of the cumulative frequencies shown in Fig. $3 \mathrm{~b}$.

The reports of the 151 accident underlying our database provide at least minimum statistical information on the probability distribution of the transverse rest position $y_{1}$ and the departure angle $y_{2}$. However, these reports tell little about the influence of accident situation and configuration of accident site on the rest position of the tank along its intended route. We will call this position the longitudinal rest position and denote it by $y_{3}$ (Fig. 2). Unfortunately, the data from the 151 accident do not allow drawing any specific conclusions about a stochastic relation between position $y_{3}$ and other two circumstantial characteristics $y_{1}$ and $y_{2}$. 
a)

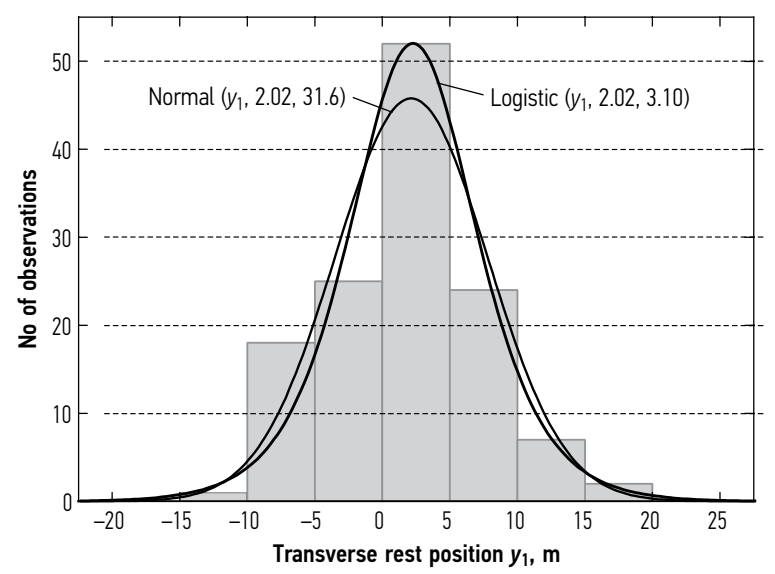

b)

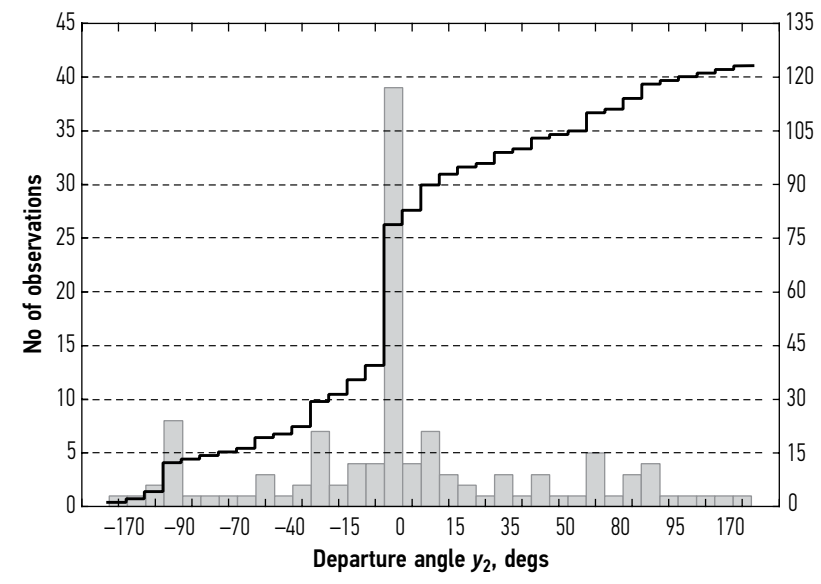

Fig. 3. Visualisation of data on road tank accidents: a - histogram of the transverse rest position values $y_{1 i}$ with superimposed normal and logistic densities; $\mathrm{b}$ - standard and cumulative histograms the of the rest departure angle values $y_{2 i}$

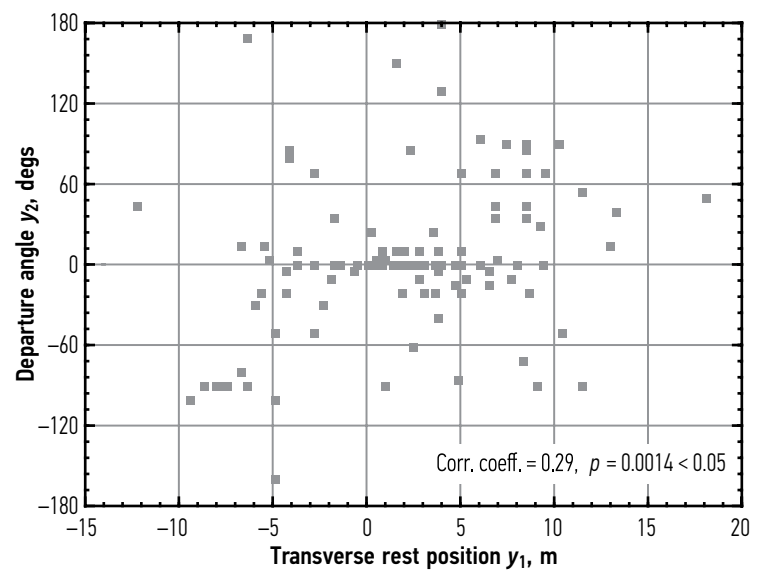

Fig. 4. Scatter diagram of the 119 observation pairs $\left(y_{1 i}, y_{2 i}\right)$

\subsection{Longitudinal Rest Position}

A road tank BLEVE will affect a relatively small territory within the transportation network. The road network fragment in this territory can be determined by introducing an unsafe distance around a vulnerable roadside object, for instance, the radius $\Delta_{\max }$ around the 'target' shown in Fig. 1. The most general and consistent criterion for the unsafe distance $\Delta_{\max }$ can be a non-exceedance of a tolerable value $P_{\max }$ of the damage probability $P(D \mid B)$ expressed as a function of the explosion stand-off $\triangle$ :

$\Delta_{\max }=\underset{\Delta}{\operatorname{argmax}}\left\{P(D \mid B, \Delta) \mid P(D \mid B, \Delta) \leq P_{\max }\right\}$.

A solution of the above maximisation problem requires to predict uncertain BLEVE effects and to utilise methods of structural reliability analysis for a repeated estimation of the damage probability $P(D \mid B, \Delta)$ for different values of $\Delta$ (see, e.g., Vaidogas, Juocevičius 2007). The determination of $\Delta_{\max }$ is beyond the scope of the present paper.

As the road network fragment defined by $\Delta_{\max }$ will be relatively small, any history of road tank accidents in this area will almost certainly not be available. Consequently, a prediction of the longitudinal rest position $y_{3}$ will have to rely on either the knowledge about road tank accidents in comparable situations or an educated guess. We think that the best way to deal with such a data situation is the predictive Bayesian approach to QRA (e.g., Aven 2003, 2009). Quantitative measures of uncertainty related to $y_{3}$ expressed in line with this approach can be integrated into a simulation-based prediction of accident locations.

\section{Monte Carlo Simulation of Accident Positions}

\subsection{Disaggregation of Road Segment}

The prediction of the longitudinal rest position $y_{3}$ can be simplified by dividing the road network fragment within $\Delta_{\max }$ into simpler shapes for which the density $f\left(y_{3}\right)$ can be assigned subjectively or on the basis of some prior knowledge. The roadway can be disaggregated into zones consisting of fixed length segments or homogenous segments in terms of roadway geometry, roadside features, traffic characteristics, etc. These zones should begin and end when their characteristics change. A disaggregation of road and rail network is basic to many applications of TRA, although the road network fragments considered in these applications are much larger than the area determined by the BLEVE-specific distance $\Delta_{\max }$ (e.g., CCPS 1995; Gheorghe et al. 2005; Samuel et al. 2009). The disaggretation of roadways is also used for an assessment of road accident likelihoods (e.g., Chang 2005).

Fig. 1 shows a simple example of a disaggregation of the road segments within $\Delta_{\max }$ into five zones with simple shapes. The width of these zones exceeds the road width to indicate that the transverse rest position of the tank can leave the road surface. In the absence of any historic data on road accidents in such zones, a uniform probability distribution of $y_{3}$ along the zone axes can be assumed for the purpose of simulation. Then the uniform density $f_{k}\left(y_{3}\right)$ will express maximum uncertainty related to the values of $y_{3}$ in the zone $k$.

The zones can be specified with relative ease for straight road segments and long horizontal curves. 
However, the specification can be conjectural and arbitrary to a degree in the road portions that have more complicated layout and/or indicate a higher proneness to road accidents. Such road portions are intersections and crossings, sharp curves, changes in the road width, wide variations in traffic volume. Roadside features (e.g., numerous roadside objects) can also have influence on zones specification.

The simulation requires to introduce a discrete probability distribution with the weights $p_{k}(k=1,2, \ldots$, $n_{k}$ ) assigned to individual zones, where $n_{k}$ is the number of zones within $\Delta_{\max }$ (e.g., $n_{k}=5$ in Fig. 1 ). The weight $p_{k}$ expresses the proneness of the zone $k$ to a road accident involving tank vehicle. In line with the predictive Bayesian approach to QRA, the weights $p_{k}$ quantify the analyst's degree of belief and can be a result of an educated guess or, alternatively, judgement based on some prior knowledge. In our opinion, there are at least four sources of such knowledge:

1. Statistical data obtaining the distribution of relative frequencies of vehicle accidents by location (intersections, non-intersections, circles, etc.) (e.g., Al-Ghamdi 2003).

2. Mathematical models used to estimate the probabilities of vehicle accidents in specific locations (Spek et al. 2006; Ye et al. 2009; Haleem et al. 2010).

3. Models relating vehicle accidents to geometric design of roadway, roadside features, traffic characteristics and environmental conditions (AbdelAty, Radwan 2000; Lee, Mannering 2002; Chang 2005; Elvik et al. 2009).

4. Methods developed for an identification of crash hotspots (e.g., Cheng, Washington 2005; Huang, Abdel-Aty 2010; Montella 2010).

The data and models just listed have potential to be used for the specification of the weights $p_{k}$. However, we think that this body of knowledge is too loose and a special study is necessary to develop more or less formal procedures which utilise the knowledge for the choice of $p_{k}$. Practical procedures for ranking and weighting the zones can be borrowed in the field of multiple criteria decision making (MCDM). For instance, the weights $p_{k}$ can be specified by organising an expert panel and utilising expert opinions by means of a well-known MCDM method called AHP (e.g., Luria, Aspinall 2003; Turskis, Zavadskas 2010; Vaidogas, Šakènaitė 2010, 2011).

\subsection{Modelling the Transverse Rest Position}

A further discrete probability distribution is necessary to choose a travel lane of the road tank. For brevity, we will consider a two-lane road only. Consequently, the distribution will have only two weights, say, $\pi_{1}$ and $\pi_{2}$. In the case where travelling frequencies of road tanks in both directions are equal, one can assume that $\pi_{1}=\pi_{2}=0.5$. If the tank vehicles travel only in one direction, $\pi_{1}=0$ or $\pi_{2}=$ 0 . With the weights $\pi_{1}$ and $\pi_{2}$ and the probability distribution of the transverse rest position $y_{1}$ obtained in Sec. 3.1, the rest position of the tank centre with respect to the road centreline, $y_{4}$, can be modelled by the mixed density:

$$
\varphi\left(y_{4} \mid \pi_{1}, \pi_{2}\right)=\pi_{1} f\left(y_{4} \mid \boldsymbol{\theta}_{1}\right)+\pi_{2} f\left(y_{4} \mid \boldsymbol{\theta}_{2}\right),
$$

where: $f(\cdot)$ is the logistic density of the transverse rest position $y_{1}$ with the parameter vectors $\boldsymbol{\theta}_{1}$ and $\boldsymbol{\theta}_{2}$ adjusted to the cross-sectional dimensions of the road. If, for instance, the lane width is equal to $3 \mathrm{~m}$ and $y_{1} \sim$ Logistic $(2.02 \mathrm{~m}, 3.10 \mathrm{~m})$, the densities $f\left(y_{4} \mid \boldsymbol{\theta}_{1}\right)$ and $f\left(y_{4} \mid \boldsymbol{\theta}_{2}\right)$ will be logistic ones with the parameter vectors:

$\boldsymbol{\theta}_{1}=(-3.52 \mathrm{~m}, 3.10 \mathrm{~m})$ and $\boldsymbol{\theta}_{2}=(3.52 \mathrm{~m}, 3.10 \mathrm{~m})$.

The logistic densities $f\left(y_{4} \mid \boldsymbol{\theta}_{1}\right)$ and $f\left(y_{4} \mid \boldsymbol{\theta}_{2}\right)$ with the above parameters are shown in Fig. 5a. This figure illustrates also the density $\varphi\left(y_{4} \mid \pi_{1}, \pi_{2}\right)$ with $\pi_{1}=0.7$ and $\pi_{2}=0.3$.

The densities $f\left(y_{4} \mid \boldsymbol{\theta}_{l}\right)(l=1$ or 2$)$ and $\varphi\left(y_{4} \mid \pi_{1}, \pi_{2}\right)$ in Eq. (4) are suited to the modelling of the transverse rest position $y_{4}$ in the case where $y_{4}$ is unbounded on both sides. However, the roadway and roadside territory can include natural and man-made obstacles which restrict the motion of vehicles after they leave the road surface or cross into opposite lanes of traffic. Examples of such obstacles are roadside barriers, medium barriers, back slopes, roadside structures.

A collision of a tank vehicle with a roadside obstacle (medium barrier) and its post-collision travel until a complete stop is a fairly uncertain process. A prediction of the transverse rest position $y_{4}$ resulting from this process is far from being trivial. However, one can say with fair degree of certainty that the obstacles, which are able to withstand an impact of a tank vehicle, determine the outermost values of $y_{4}$. Let these values be $y_{4 L}$ and $y_{4 R}$. Then for the purposes of simulation one can assume that $y_{4} \in\left[y_{4 L}, y_{4 R}\right]$ when obstacles are on both sides of the travel lane and $y_{4} \in\left[y_{4 L}, \infty\left[\right.\right.$ or $\left.\left.y_{4} \in\right]-\infty, y_{4 R}\right]$ when the obstacles are on the left or the right side, respectively. An illustration of $y_{4 L}$ and $y_{4 R}$ for a two lane road is shown in Fig. 5b, where $y_{4 L}=9 \mathrm{~m}$ and $y_{4 R}=-12 \mathrm{~m}$ for the lane 1 and $y_{4 L}=-12 \mathrm{~m}$ and $y_{4 R}=9 \mathrm{~m}$ for the lane 2 .

Fitting a probability distribution of $y_{4}$ over the twosided or one-sided intervals introduced above can be problematic. A relatively large amount of data required by standard fitting procedures will hardly be available for the reasons mentioned in Sec. 3.1. In addition, accident situations involving roadside obstacles are unique and this raises the question, whether the data collected in one roadside situation is representative to another situations. However, the fact that values of $y_{4}$ are bounded by the values $y_{4 L}$ and $y_{4 R}$ suggests that the probability distribution of $y_{4}$ can be obtained by truncating the densities $f\left(y_{4} \mid \boldsymbol{\theta}_{l}\right)$. The truncated density $f^{\prime}\left(y_{4} \mid \boldsymbol{\theta}_{l}\right)$ is obtained from $f\left(y_{4} \mid \boldsymbol{\theta}_{l}\right)$ by means of the standard relations:

$$
f^{\prime}\left(y_{4}\right)=\left\{\begin{array}{lll}
\frac{f\left(y_{4}\right)}{F\left(y_{4 R}\right)-F\left(y_{4 L}\right)} & \text { if } \left.y_{4} \in\right] y_{4 L}, y_{4 R}[, \\
\frac{f\left(y_{4}\right)}{1-F\left(y_{4 L}\right)} & \text { if } \left.y_{4} \in\right] y_{4 L}, \infty[, \\
\frac{f\left(y_{4}\right)}{F\left(y_{4 R}\right)} & \text { if } \left.y_{4} \in\right]-\infty, y_{4 R}[.
\end{array}\right.
$$



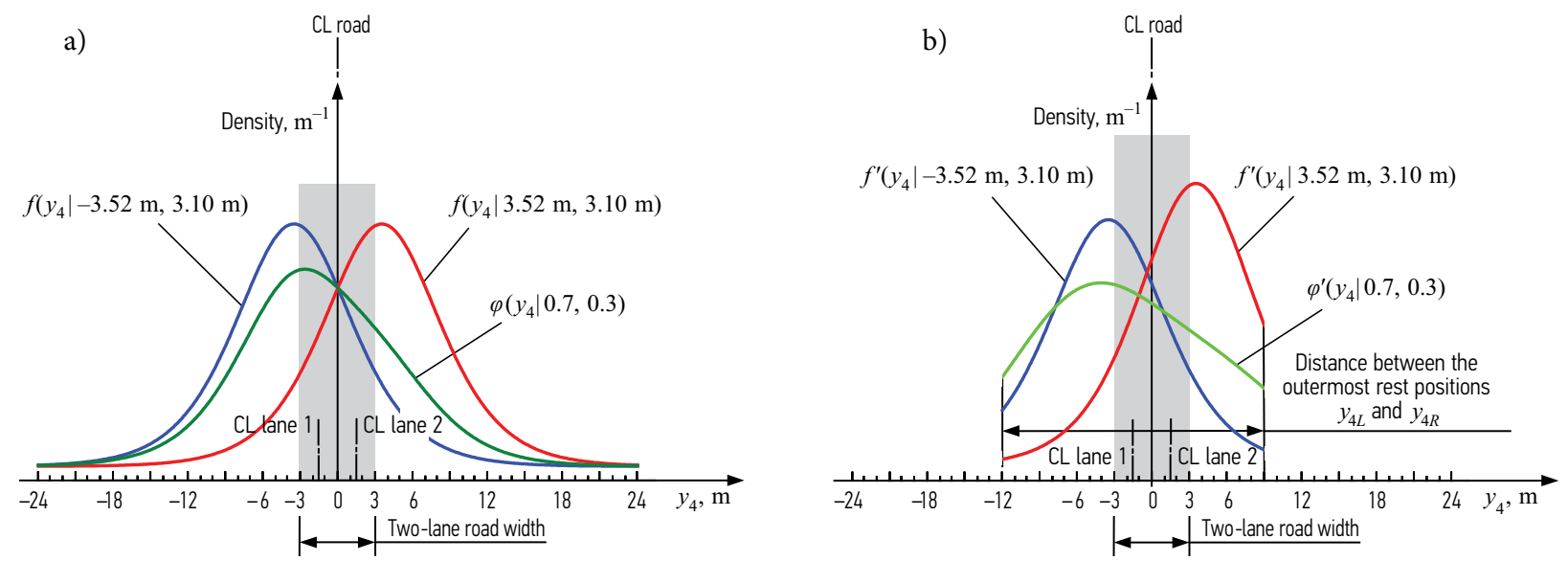

Fig. 5. An illustration of the densities expressing uncertainties in the transverse rest position $y_{4}$ with respect to the centreline of a two-lane road: a - standard densities; $\mathrm{b}$ - truncated densities

In the above relations, $F\left(y_{4}\right)$ is the cumulative distribution function of $y_{4}$ and the parameter vector $\boldsymbol{\theta}_{l}$ is skipped for brevity. With the truncated densities related to opposite lanes, the truncated density related to the whole width of a two-lane road is obtained by:

$$
\varphi^{\prime}\left(y_{4} \mid \pi_{1}, \pi_{2}\right)=\pi_{1} f^{\prime}\left(y_{4} \mid \boldsymbol{\theta}_{1}\right)+\pi_{2} f^{\prime}\left(y_{4} \mid \boldsymbol{\theta}_{2}\right) .
$$

The density $\varphi^{\prime}\left(y_{4} \mid \pi_{1}, \pi_{2}\right)$ is defined on the same interval as the constituent densities $f^{\prime}\left(y_{4} \mid \boldsymbol{\theta}_{l}\right)$ (see Eq. (6)).

Fig. 5b presents an illustration of the densities $f^{\prime}\left(y_{4} \mid \boldsymbol{\theta}_{1}\right)$ and $f^{\prime}\left(y_{4} \mid \boldsymbol{\theta}_{2}\right)$ obtained by a truncation of a standard logistic density. The densities $f^{\prime}\left(y_{4} \mid \boldsymbol{\theta}_{1}\right)$ and $f^{\prime}\left(y_{4} \mid \boldsymbol{\theta}_{2}\right)$ are defined on the intervals $\left(y_{4 L}, y_{4 R}\right)=(9 \mathrm{~m},-12 \mathrm{~m})$ and $\left(y_{4 L}, y_{4 R}\right)=(-12 \mathrm{~m}, 9 \mathrm{~m})$, respectively. Fig. 5b shows also the density $\varphi^{\prime}\left(y_{4} \mid 0.7,0.3\right)$ calculated by means of Eq.(7).

The outermost rest positions $y_{4 L}$ and $y_{4 R}$ may not necessarily be fixed values. Such obstacles as trees and bushes planted in the roadside territory with moderate density may stop the motion of a tank vehicle after its departure from the road. Obstacles of this type may have randomly distributed distances from the road edge. In addition, the depth of a vehicle encroachment into the area of such obstacles may be highly random. Consequently, the outermost rest positions $y_{4 L}$ and $y_{4 R}$ may be uncertain quantities. They can be modelled as random variables with respective densities $f\left(y_{4 L}\right)$ and $f\left(y_{4 R}\right)$. Fig. 6 shows an illustration of the density $f\left(y_{4 R}\right)$ and the truncation point $y_{4 R j}$ sampled from a probability distribution represented by $f\left(y_{4 R}\right)$.

\subsection{Algorithm of the Simulation}

With the models described in this section, the stochastic simulation of the tank rest position will consist in sampling values of the tank rest position and departure angle from underlying probability distributions. Each loop of the stochastic simulation of accident position, say, loop $j$ should start from sampling of the zone number $k$ from the discrete probability distribution defined by the weights $p_{k}$ (Fig. 7). Then the values of the longi-

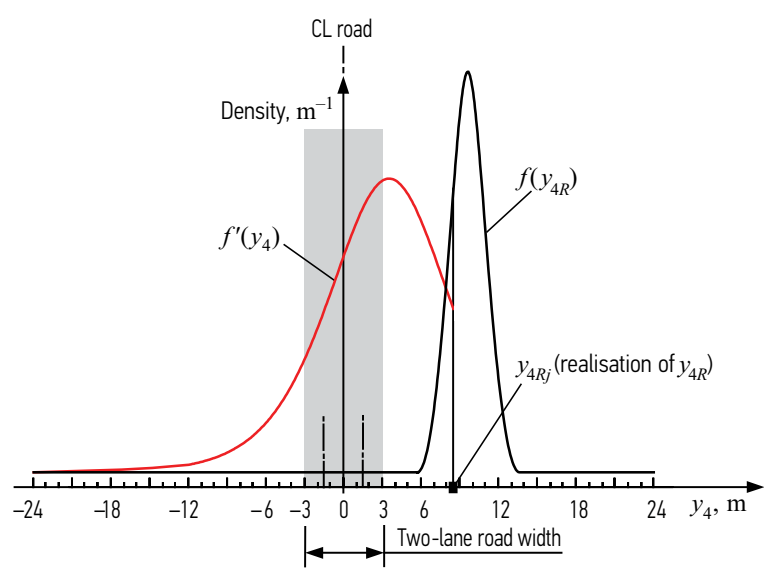

Fig. 6. The case of the density of the transverse rest position $y_{4}$ truncated at a random point

tudinal and transverse position, $y_{3 j}$ and $y_{4 j}$, must be sampled from corresponding probability distributions. This operation will be straightforward in case where $y_{3}$ and $y_{4}$ are considered to be independent. Finally the value of the departure angle $y_{2 j}$ can be sampled.

An application of the proposed simulation procedure with the flowchart shown in Fig. 7 is presented in the second part of this study (see next issue of the Journal). The case study described in the second part applies the procedure to an existing site of the potential BLEVE accident located in the coastal region of Lithuania.

\section{Conclusions}

A prediction of the road tank accidents capable to escalate into explosions on road has been considered. The attention was focussed on boiling liquid expanding vapour explosions (BLEVEs). The potential damage caused by BLEVEs to roadside objects depends on distance and orientation of an exploding tank in relation to an exposed object. Consequently, an assessment of the damage will require predicting the position of the tank within a road segment going in the vicinity of a vulnerable roadside object. 


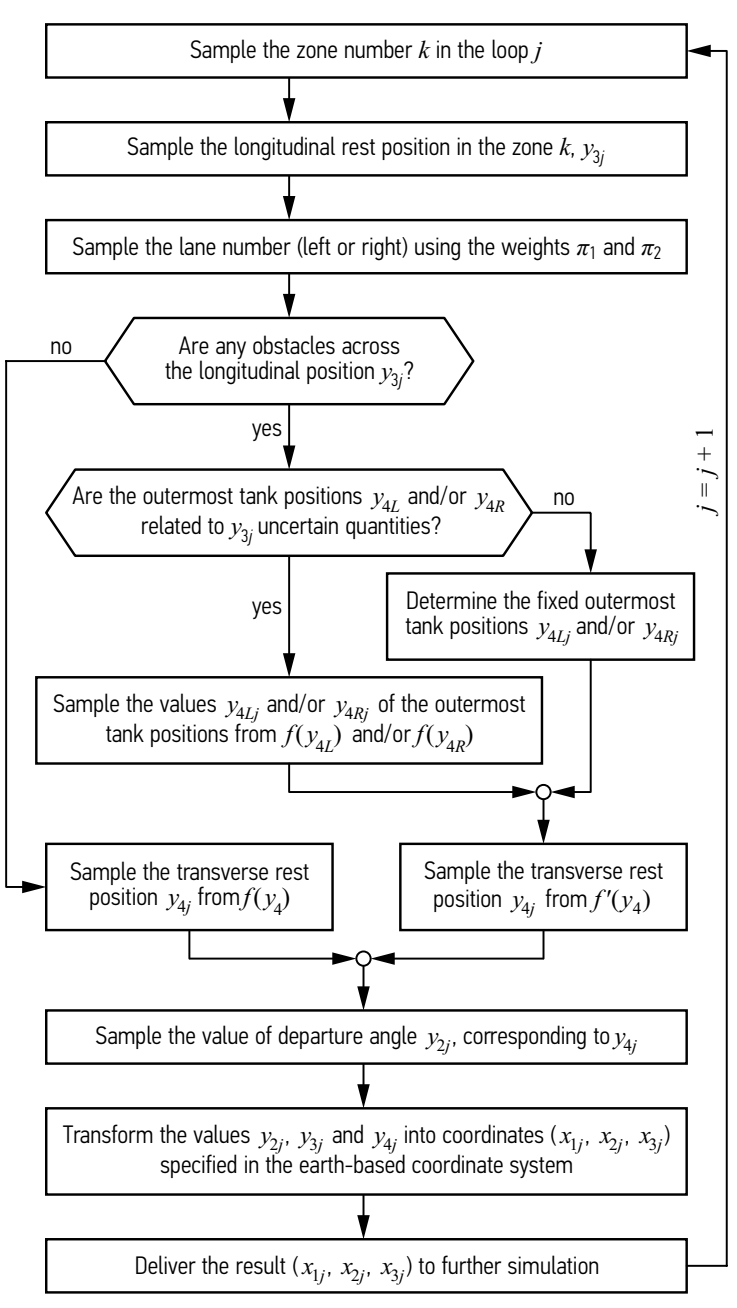

Fig. 7. A flowchart of the simulation step $j$

The prediction of the position of road tank explosions can be subdivided into the prediction of three circumstantial characteristics: longitudinal and transverse rest positions of the tank with respect to road centreline or other longitudinal reference line as well as departure angle of the tank. These three characteristics are uncertain quantities and uncertainty related to them must be modelled by means probability distributions. Some of these distributions can be fitted to statistical data; others will have to be specified subjectively in line with the principles of a quantitative risk assessment (QRA).

Any systematic set of data on the position of road tanks which underwent BLEVEs is not available or, at least, accessible. BLEVEs on road are rare, unexpected and short-lasting events, in the course of which tanks are destroyed. However, data on transverse rest position and departure angle can be gained from accidents which were precursors of BLEVEs or accidents of non-explosive tanks which were similar to tanks capable of causing BLEVEs. It was possible to extract such data from reports on past road tank accidents presented in the mass-media and on the internet. Data on 151 road tank accidents collected from these sources allowed us to fit a logistic probability distribution for the transverse rest position and to establish empirical probability distribu- tion for the departure angle. The stochastic dependence between these two circumstantial characteristics is weak, albeit statistically significant.

A probabilistic modelling of the tank rest position along a road segment, from which BLEVE can affect a vulnerable roadside object, is problematic in terms of data. Such a road segment will be relatively small and data on tank accidents in this or similar segments will hardly be available. Consequently, the probability distribution of the longitudinal rest position will have to be chosen subjectively. Methods of the specification of subjective probabilities and probability distributions developed and widely applied in the field of QRA can be used for the modelling of the longitudinal rest position.

An assessment of damage caused by BLEVEs on road and rail is in essence a QRA problem. An estimation of risk posed by these events will require to choose among two basic approaches to QRA, namely, classical Bayesian approach and predictive Bayesian approach. All probabilistic models presented in this study were interpreted in the context of the predictive Bayesian approach. We think that this approach allows to deal effectively with sparseness of data on past road tank BLEVEs and the need to apply extensively judgement to the prediction of such accidents. However, an extensive discussion on why the predictive Bayesian approach was preferred to the classical Bayesian approach was not presented here. Such a discussion can be found in numerous publications dedicated to methodological issues of QRA.

\section{References}

Abbasi, T.; Abbasi, S. A. 2007. The boiling liquid expanding vapour explosion (BLEVE): mechanism, consequence assessment, management, Journal of Hazardous Materials 141(3): 489-519. http://dx.doi.org/10.1016/j.jhazmat.2006.09.056

Abdel-Aty, M. A.; Radwan, A. E. 2000. Modelling traffic accident occurrence and involvement, Accident Analysis and Prevention 32(5): 633-642. http://dx.doi.org/10.1016/S0001-4575(99)00094-9

Abdolhamidzadeh, B.; Abbasi, T.; Rashtchian, D.; Abbasi, S. A. 2011. Domino effect in process-industry accidents - an inventory of past events and identification of some patterns, Journal of Loss Prevention in the Process Industries 24(5): 575-593. http://dx.doi.org/10.1016/j.jlp.2010.06.013

Abdolhamidzadeh, B.; Abbasi, T.; Rashtchian, D.; Abbasi, S. A. 2010. A new method for assessment domino effects in chemical process industry, Journal of Hazardous Materials 182(1-3): 416-426. http://dx.doi.org/10.1016/j.jhazmat.2010.06.049

Al-Ghamdi, A. S. 2003. Analysis of traffic accidents at urban intersections in Riyadh, Accident Analysis and Prevention 35(5): 717-724.

http://dx.doi.org/10.1016/S0001-4575(02)00050-7

Aven, T. 2003. Foundations of Risk Analysis: A Knowledge and Decision-Oriented Perspective. 1st edition. Wiley. 206 p.

Aven, T. 2009. Perspectives on risk in a decision-making context - review and discussion, Safety Science 47(6): 798-806. http://dx.doi.org/10.1016/j.ssci.2008.10.008

Aven, T.; Zio, E. 2011. Some considerations on the treatment of uncertainties in risk assessment for practical decision making, Reliability Engineering and System Safety 96(1): 64-74. http://dx.doi.org/10.1016/j.ress.2010.06.001 
Birk, A. M. 1996. Hazards from propane BLEVEs: An update and proposal for emergency responders, Journal of Loss Prevention in the Process Industries 9(2): 173-181. http:// dx.doi.org/10.1016/0950-4230(95)00046-1

Bubbico, R.; Di Cave, S.; Mazzarotta, B. 2004a. Risk analysis for road and rail transport of hazardous materials: a simplified approach, Journal of Loss Prevention in the Process Industries 17(6): 477-482. http://dx.doi.org/10.1016/j.jlp.2004.08.010

Bubbico, R.; Di Cave, S.; Mazzarotta, B. 2004b. Risk analysis for road and rail transport of hazardous materials: a GIS approach, Journal of Loss Prevention in the Process Industries 17(6): 483-488. http://dx.doi.org/10.1016/j.jlp.2004.08.011

Casal, J. 2007. Evaluation of the Effects and Consequences of Major Accidents in Industrial Plants. 1st edition. Elsevier Science. 378 p.

Casal, J.; Salla, J. M. 2006. Using liquid superheat energy for a quick estimation of overpressure in BLEVEs and similar explosions, Journal of Hazardous Materials 137(3): 13211327. http://dx.doi.org/10.1016/j.jhazmat.2006.05.001

CCPS 1994. Guidelines for Evaluating the Characteristics of $\mathrm{Va}$ por Cloud Explosions, Flash Fires, and BLEVEs. 1st edition. Wiley-AIChE. 260 p.

CCPS 1995. Guidelines for Chemical Transportation Risk Analysis. 1st edition. Wiley-AIChE. $382 \mathrm{p}$.

Chang, L.-Y. 2005. Analysis of freeway accident frequencies: Negative binomial regression versus artificial neural network, Safety Science 43(8): 541-557. http://dx.doi.org/10.1016/j.ssci.2005.04.004

Cheng, W.; Washington, S. P. 2005. Experimental evaluation of hotspot identification methods, Accident Analysis and Prevention 37(5): 870-881. http://dx.doi.org/10.1016/j.aap.2005.04.015

CPD 1992. Methods for the Determination of Possible Damage to People and Objects from Releases of Hazardous Materials - 'Green Book'. The Hague: Committee for the Prevention of Disasters.

CPD 1999. Guidelines for Quantitative Risk Assessment 'Purple Book'. Publication Series on Dangerous Substances (PGS3). The Hague: Committee for the Prevention of Disasters.

CPD 2005. Methods for the Calculation of Physical Effects due to Releases of Hazardous Materials (Liquids and Gases) 'Yellow Book'. Publication Series on Dangerous Substances (PGS2). The Hague: Committee for the Prevention of Disasters.

Elvik, R.; Høye, A.; Vaa, T.; Sørensen, M. 2009. The Handbook of Road Safety Measures. 2nd edition. Emerald Group Publishing Limited. $1124 \mathrm{p}$.

Evans, M.; Hastings, N.; Peacock, B. 2000. Statistical Distributions. 3rd edition. Wiley-Interscience. $221 \mathrm{p}$.

Fabiano, B.; Currò, F.; Palazzi, E.; Pastorino, R. 2002. A framework for risk assessment and decision-making strategies in dangerous good transportation, Journal of Hazardous Materials 93(1): 1-15. http://dx.doi.org/10.1016/S0304-3894(02)00034-1

Franck, H.; Franck, D. 2009. Mathematical Methods for Accident Reconstruction: A Forensic Engineering Perspective. CRC Press. 328 p.

Garrick, B. J. 2008. Quantifying and Controlling Catastrophic Risks. Academic Press. 376 p.

Genova, B.; Silvestrini, M.; Trujillo, L. F. J. 2008. Evaluation of the blast-wave overpressure and fragments initial velocity for a BLEVE event via empirical correlations derived by a simplified model of released energy, Journal of Loss Prevention in the Process Industries 21(1): 110-117.

http://dx.doi.org/10.1016/j.jlp.2007.11.004

Gheorghe, A. V.; Birchmeier, J.; Vamanu, D.; Papazoglou, I.; Kröger, W. 2005. Comprehensive risk assessment for rail transportation of dangerous goods: a validated platform for decision making, Reliability Engineering and System Safety 88(3): 247-272. http://dx.doi.org/10.1016/j.ress.2004.07.017

Gubinelli, G.; Zanelli, S.; Cozzani, V. 2004. A simplified model for the assessment of the impact probability of fragments, Journal of Hazardous Materials 116(3): 175-187. http://dx.doi.org/10.1016/j.jhazmat.2004.09.002

Gubinelli, G.; Cozzani, V. 2009. Assessment of missile hazards: evaluation of the fragment number and drag factors, Journal of Hazardous Materials 161(1): 439-449.

http://dx.doi.org/10.1016/j.jhazmat.2008.03.116

Hauptmanns, U. 2001. A procedure for analyzing the flight of missiles from explosions of cylindrical vessels, Journal of Loss Prevention in the Process Industries 14(5): 395-402. http://dx.doi.org/10.1016/S0950-4230(01)00011-0

Haleem, K.; Abdel-Aty, M.; Mackie, K. 2010. Using a reliability process to reduce uncertainty in predicting crashes at unsignalised intersections, Accident Analysis and Prevention 42(2): 654-666. http://dx.doi.org/10.1016/j.aap.2009.10.012

Huang, H.; Abdel-Aty, M. 2010. Multilevel data and Bayesian analysis in traffic safety, Accident Analysis and Prevention 42(6): 1556-1565.

http://dx.doi.org/10.1016/j.aap.2010.03.013

Juocevičius, V.; Vaidogas, E. R. 2010. Effect of explosive loading on mechanical properties of concrete and reinforcing steel: towards developing a predictive model, Mechanika (1): 5-12.

Kumamoto, H. 2011. Satisfying Safety Goals by Probabilistic Risk Assessment. Springer. 269 p.

Lee, J.; Mannering, F. 2002. Impact of roadside features on the frequency and severity of run-off-roadway accidents: an empirical analysis, Accident Analysis and Prevention 34(2): 149-161. http://dx.doi.org/10.1016/S0001-4575(01)00009-4

Lee, K. H.; Rosowsky, D. V. 2006. Fragility analysis of woodframe buildings considering combined snow and earthquake loading, Structural Safety 28(3): 289-303. http://dx.doi.org/10.1016/j.strusafe.2005.08.002

Luria, P.; Aspinall, P. A. 2003. Evaluating a multi-criteria model for hazard assessment in urban design. The Porto Marghera case study, Environmental Impact Assessment Review 23(5): 625-653. http://dx.doi.org/10.1016/S0195-9255(03)00091-X

Mébarki, A.; Mercier, F.; Nguyen, Q. B.; Ami Saada, R. 2009. Structural fragments and explosions in industrial facilities. Part I: Probabilistic description of the source terms, Journal of Loss Prevention in the Process Industries 22(4): 408-416. http://dx.doi.org/10.1016/j.jlp.2009.02.006

Montella, A. 2010. A comparative analysis of hotspot identification methods, Accident Analysis and Prevention 42(2): 571-581. http://dx.doi.org/10.1016/j.aap.2009.09.025

Nguyen, Q. B.; Mebarki, A.; Ami Saada, R.; Mercier, F.; Reimeringer, M. 2009. Integrated probabilistic framework for domino effect and risk analysis, Advances in Engineering Software 40(9): 892-901. http://dx.doi.org/10.1016/j.advengsoft.2009.01.002

Oggero, A.; Darbra, R. M.; Darbra, R. M.; Muñoz, M.; Planas, E.; Casal, J. 2006. A survey of accidents occurring during the transport of hazardous substances by road and rail, Journal of Hazardoud Materials 133(1-3): 1-7. http://dx.doi.org/10.1016/j.jhazmat.2005.05.053 
Paltrinieri, N.; Landucci, G.; Molag, M.; Bonvicini, S.; Spadoni, G.; Cozzani, V. 2009. Risk reduction in road and rail LPG transportation by passive fire protection, Journal of Hazardous Materials 167(1-3): 332-344.

http://dx.doi.org/10.1016/j.jhazmat.2008.12.122

Planas-Cuchi, E.; Gasulla, N.; Ventosa, A.; Casal, J. 2004. Explosion of a road tanker containing liquefied natural gas, Journal of Loss Prevention in the Process Industries 17(4): 315-321. http://dx.doi.org/10.1016/j.jlp.2004.05.005

Prugh, R. W. 1991. Quantitative evaluation of "BLEVE" hazards, Journal of Fire Protection Engineering 3(1): 9-24. http://dx.doi.org/10.1177/104239159100300102

Prugh, R. W. 1994. Quantitative evaluation of fireball hazards, Process Safety Progress 13(2): 83-91. http://dx.doi.org/10.1002/prs.680130211

Roberts, T.; Gosse, A.; Hawksworth, S. 2000. Thermal radiation from fireballs on failure of liquefied petroleum gas storage vessels, Process Safety and Environmental Protection 78(3): 184-192. http://dx.doi.org/10.1205/095758200530628

Samuel, C.; Keren, N.; Shelley, M. C.; Freeman, S. A. 2009. Frequency analysis of hazardous material transportation incidents as a function of distance from origin to incident location, Journal of Loss Prevention in the Process Industries 22(6): 783-790. http://dx.doi.org/10.1016/j.jlp.2009.08.013

Spek, A. C. E.; Wieringa, P. A.; Janssen, W. H. 2006. Intersection approach speed and accident probability, Transportation Research Part F: Traffic Psychology and Behaviour 9(2): 155-171. http://dx.doi.org/10.1016/j.trf.2005.10.001

Taveau, J. 2010. Risk assessment and land-use planning regulations in France following the AZF disaster, Journal of Loss Prevention in the Process Industries 23(6): 813-823. http://dx.doi.org/10.1016/j.jlp.2010.04.003

Trépanier, M.; Leroux, M.-H.; De Marcellis-Warin, N. 2009. Cross-analysis of hazmat road accidents using multiple databases, Accident Analysis and Prevention 41(6): 11921198. http://dx.doi.org/10.1016/j.aap.2008.05.010

Turskis, Z.; Zavadskas, E. K. 2010. A new fuzzy additive ratio assessment method (ARAS-F). Case study: the analysis of fuzzy multiple criteria in order to select the logistic canters location, Transport 25(4): 423-432.

http://dx.doi.org/10.3846/transport.2010.52

Vaidogas, E. R. 2009. On applying sparse and uncertain information to estimating the probability of failure to rare abnormal situations, Information Technology and Control 38(2): 135-146.

Vaidogas, E. R. 2006. First step towards preventing losses due to mechanical damage from abnormal actions: knowledgebased forecasting the actions, Journal of Loss Prevention in the Process Industries 19(5): 375-385. http://dx.doi.org/10.1016/j.jlp.2005.10.002

Vaidogas, E. R. 2007a. Prediction of Accidental Actions Likely to Occur on Building Structures. An Approach Based on Stochastic Simulation. Vilnius: Technika. 247 p. http://dx.doi.org/10.3846/1373-M

Vaidogas, E. R. 2007b. Handling uncertainties in structural fragility by means of the Bayesian bootstrap resampling, in Proceedings of the 10th International Conference on Applications of Statistics and Probability in Civil Engineering (ICASP10), Tokyo, Japan, Jul 31 - Aug 03, 2007, Eds. J. Kanda, T. Takada, H. Furuta. London: Taylor \& Francis (CD).

Vaidogas, E. R. 2003. Accidental explosions: Bayesian uncertainty handling in assessing damage to structures, in Proceedings of the 9th International Conference on Applications of Statistics and Probability in Civil Engineering, July 6-9,
2003, San Francisco, CA, Eds. A Der Kiureghian, S. Madanat, J. M. Pestana. Rotterdam: Milpress Science Publishers, Vol. 1, 191-198.

Vaidogas, E. R.; Juocevičius, V. 2009. Assessment of structures subjected to accidental actions using crisp and uncertain fragility functions, Journal of Civil Engineering and Management 15(1): 95-104. http://dx.doi.org/10.3846/1392-3730.2009.15.95-104

Vaidogas, E. R.; Juocevičius, V. 2008a. Reliability of a timber structure exposed to fire: estimation using fragility function, Mechanika (5): 35-42.

Vaidogas, E. R.; Juocevičius, V. 2008b. Sustainable development and major industrial accidents: the beneficial role of risk-oriented structural engineering, Technological and Economic Development of Economy 14(4): 612-627. http://dx.doi.org/10.3846/1392-8619.2008.14.612-627

Vaidogas, E. R.; Juocevičius, V. 2007. Assessing external threats to structures using limited statistical data: an approach based on data resampling, Technological and Economic Development of Economy 13(2): 170-175.

Vaidogas, E. R.; Šakenaitè, J. 2010. Protecting built property against fire disasters: multi-attribute decision making with respect to fire risk, International Journal of Strategic Property Management 14(4): 391-407. http://dx.doi.org/10.3846/ijspm.2010.29

Vaidogas, E. R.; Šakènaitè, J. 2011. Multi-attribute decisionmaking in economics of fire protection, Inzinerine Ekonomika - Engineering Economics 22(3): 262-270. http://dx.doi.org/10.5755/j01.ee.22.3.516

Ye, X.; Pendyala, R. M.; Washington, S. P.; Konduri, K.; Oh, J. 2009. A simultaneous equations model of crash frequency by collision type for rural intersections, Safety Science 47(3): 443-452. http://dx.doi.org/10.1016/j.ssci.2008.06.007 